\title{
Sailing in the same ship? Differences in factors motivating piracy of music and movie content
}

\begin{abstract}
This study presents indicative evidence on the impact of a range of consumer attitudes and characteristics upon the consumption of pirated music and movie files. Consumers of both types of content are analyzed using a survey sample consisting of over 6,100 observations. The study finds that demographic factors and attitudes towards downloaded content have the greatest influence on the consumption of pirated material, while awareness of legality and the threat of punishment affect consumption to a lesser extent. The findings of this study also suggest several conspicuous contrasts in the consumption of illegally downloaded music and movie files. Prolific music downloaders typically demonstrate a greater propensity to substitute legal content for pirated materials, while heavy movie downloaders demonstrate a greater willingness to pay for legal alternatives and are deterred to a greater extent by an awareness of negative effects of piracy upon the movie industry.
\end{abstract}

Keywords: File-sharing, illegal downloading, piracy, music, movies

JEL Codes: C31, D12, K42, L82, Z10 


\section{Sailing in the same ship? Differences in factors motivating piracy of music and movie content}

\section{Introduction}

File sharing is the act of distributing digital materials between groups of users. Shared content often takes the form of entertainment media ripped from an original copyrighted source such as a commercial CD or DVD, where it is illegal to share these files without the consent of the copyright owner. A popular mechanism for accessing pirated materials online is the BitTorrent protocol, whereby users share components of the same file simultaneously through networks that reduce the strain on any single user's Internet bandwidth. Torrent files indicating the location of external trackers are downloaded via websites such as The Pirate Bay, Kick-Ass Torrents and TorrentReactor, which typically do not accept any legal liability as the copyrighted material is not actually hosted on their servers. Additionally, with the technological frontier constantly shifting, illegal file sharing is increasingly being facilitated via other mechanisms, such as newsgroups, blogs and direct download sites.

The piracy of copyrighted material is a major issue of concern for governments and policy makers, as well as the creative industries who represent themselves as victims of such activities. The scale of the problem has become vast, with peer-to-peer (P2P) file sharing interactions accounting for between an estimated half and four-fifths of all internet traffic and over ninety-five per cent of overnight activity (Schuloze \& Mochalski, 2007). Consumer attitudes towards illegal file-sharing seem to suggest a high level of moral ambivalence toward the practice, with previous research showing that two-thirds of illegal file sharers in the US are unconcerned whether files are copyrighted or not (Pew Internet and American Life Project, 2003) and only around five percent of the so-called Generation Y holds the belief 
that illegally downloading copyrighted material is ethically or morally objectionable (Freestone \& Mitchell, 2004). Additionally, it has been suggested that seventy per cent of surveyed 16-19 year olds do not feel any guilt about illegally downloading music tracks, while sixty-one per cent of the same age group do not believe that they should have to pay for music at all (Human Capital, 2009).

Prior research into illegal file sharing has tended to focus on the piracy of music files, with comparatively little attention paid to piracy of movies and even less to any formal comparison between the two types of behavior. Most other studies either explicitly focus on one type of piracy or assume these activities to be indistinguishable. The aim of this paper is to explicitly differentiate between the factors motivating piracy of music and movies through testing the following research question: Are there significant differences between the factors affecting the likelihood of pirating larger volumes of music and movie files?

Three other features of this study make a significant contribution to the body of literature on illegal file sharing behavior. First, the survey evidence used in this study draws on a wider cross-section of society in comparison to the many others that restrict their enquiries to relatively small groups of college students. Second, the empirical analysis is based on a larger number of observations $(\mathrm{N}=6,103)$ than is found in similar research. Finally, the use of a Finnish dataset responds in part to calls from within the literature for both analyses outside of the USA and UK (Shanahan \& Hyman, 2010), as well as in a range of markets beyond music (Huang, 2005).

The empirical analysis in this study essentially derives a demand function for pirated media while controlling for a variety of social and demographic factors. Although the direct price for illegal downloads is zero, other elements of a generalized price expression are included to represent the cost of consumption at the margin, such as the expected cost punishment. These are related to the banded quantity of consumption for each consumer to 
derive an effective demand function that also measures the marginal impact of a range of incentives (social, financial, etc.) and disincentives (such as poor relative quality of content) upon behavior.

\section{Method}

This study uses an online survey into digital piracy to distinguish between differing incentives for pirating music and movies. The survey was conducted by the Helsinki Institute of Information Technology (HIIT) in August 2007 and was advertised to the public for a period of seven days through the media group Sanoma's websites, as well as their technology and business magazines. The primary survey questions asked respondents to reveal the extent to which they had engaged in the piracy of music and movie files, measured in terms of the number of files illegally downloaded over their lifetime. The survey also identified respondents' demographic and social characteristics and asked participants to answer a range questions relating to behaviors and attitudes towards piracy and illegal file sharing.

The results of the survey were made publically available online by HIIT and include 6,103 individual responses. Due to the nature of the subject and channels used to advertise its existence, the survey is best regarded as a self-selecting opinion poll. This is because respondents may be more predisposed to illegal file sharing than the general population and consequently be less representative in terms of age, gender, etc. However, despite the clear bias of younger males in the survey sample, the dataset employed is representative of the demographic for which there is perhaps the greatest need to understand motivation.

A further possible concern relates to the self-admissive nature of the data, in that the survey only records the respondent's stated patterns of use, which may not accurately reflect their actual behavior. While this is a general problem encountered in surveys of illegal activity, respondents to this particular survey arguably have less need to camouflage their 
responses compared with those committing other crimes (e.g. sexual or violent offences). The dataset can only be claimed to represent a convenient sample of opinions, attitudes and behaviors that can help explore a range of theoretical expectations in relation to the demand for illegally obtained media. The results are merely intended to be indicative of prevailing attitudes and behaviors within this particular group of respondents and do not necessarily offer the sort of definitive conclusions that could be identified using a fully representative sample. Owing to the nature of the subject matter, the authors feel that the evidence presented in this paper is sufficiently compelling to warrant further investigation and discussion.

A series of ordinal logistic regressions are specified based on the responses to the HIIT survey. This technique can be used to reveal the effect of a range of independent variables describing respondents' characteristics upon the value of a dependent variable, which here represents the quantity of different file types illegally downloaded measured on a rising scale between 0 and 4 (see Table 1). In the regression which assesses music downloads, this ordered variable represents the volume of whole albums downloaded illegally by respondents over time. For movie downloads, the response band represents individual movie titles illegally downloaded. With respect to both the music and movie variables, the proportion of the sample suggesting they had never downloaded an album or movie in the past is approximately twenty per cent.

Table 1 here.

A majority of the remaining survey questions require the respondent to state the extent to which they agree with a given statement or sentiment using a Likert scale. A principal component analysis is conducted on the vast number of these attitudinal responses 
to construct the independent variables used in the regression analysis. This factor analysis is primarily undertaken so as to avoid any issues relating to multicollinearity between variables that are each determined by the same underlying attitudes and has the added benefit of preserving degrees of freedom.

Table 2 contains detailed information on the sixteen attitudinal factors that are retained for the purposes of the exploratory regression analysis. The identified factors are presented in descending order of their Eigenvalue (all in excess of 1), where the respective Cronbach's alpha values suggest that a majority of the factors have an acceptable or better level of consistency. Descriptive statistics for the set of variables used to control for sociodemographic factors are also presented in this table.

Table 2 here.

\section{General results}

Output from two ordinal logistic regressions is presented in Table 3, where the functional forms are identical aside from the choice of dependent variable. The discrete categories for the limited dependent variables recorded by the survey make precise interpretation of the magnitudes of estimated coefficients difficult. For example, if this variable takes a value of four, this does not necessarily mean that the given respondent downloads twice the amount of material as those expressing a value of two. Therefore, the interpretation of this regression output allows only for the comparison of relative magnitudes between coefficients appearing in each of the regressions, as well as the level of statistical

significance. Table 3 presents the estimated coefficients: one, two or three star notation indicates statistical significance at the $95 \%, 99 \%$ and $99.9 \%$ confidence intervals respectively. 
Table 3 here.

The estimated coefficients for control variables capturing relevant demographic information accord with theoretical expectations. Age and gender are found to be significant predictors of piracy, in that females and older respondents demonstrate a reduced likelihood of having downloaded large quantities of materials. These findings are consistent with the consensus expressed elsewhere in the literature relating to the typical demographic profile of pirates (Sims, Cheng \& Teegan, 1996).

The estimated coefficients attached to the income dummies (Y1500, Y2500 etc.) show that demand for illegal downloads peaks among the middle of the income range. This is presumably because paid consumption of legal material does not present a significant opportunity cost for those on a very high income, while those with very low incomes may be constrained by a lack of available technology (internet access, transfer speed and storage capacity) and expertise. Area of residency is not found to significantly explain variation in the quantity of files downloaded illegally.

Coefficients attached to the sixteen attitudinal factors can be grouped into a number of distinct categories to allow for ease of interpretation. The first such category of variables relates to the perceived relative quality of pirated materials compared to legal alternatives (NEGP2P, POSLEGAL). The estimated coefficients attached to these variables unequivocally suggest that consumers with a more negative outlook on illegal content and a more positive view of legal download services are significantly less likely to pirate large quantities of music and movie files. These results are both entirely intuitive and consistent with the findings of other studies. File sharing networks are typically shown to invite low quality content (Parameswaran, Susarla \& Whinston, 2001) that compares unfavorably to that which is legally purchased (Hirshleifer \& Riley, 1992). Our findings also support the 
rationale for content owners to 'poison' P2P files, as highlighted by studies such as Christin, Weigend \& Chuang (2005) and LaRose et al. (2005). Improving the functionality of legal download sites has also previously been found to act as a significant disincentive to commit piracy (Sinha \& Mandel, 2008).

The second category of variables relate to financial incentives for piracy (SAVINGS, IMPLEG, WTPALT). These estimated variable coefficients support the argument that perceived monetary and time savings strongly incentivize the consumption of larger volumes of pirated materials. It is particularly noteworthy that a significant contributor to the SAVINGS factor is a belief that piracy affords access to material before general release in Finland. To some extent, this finding is indicative that file sharers observe a significant disparity in the catalogues of works available legally and illegally and in the case of movies, a substantial delay between worldwide cinematic and home release. Thus, attempts to encourage illegal file sharers towards legal distribution channels could emphasize the existance of a wider selection of material and more timely release of output across global territories. These findings are also largely consistent with many other studies into the illegal consumption of both music (Hui \& Png, 2003; Hong, 2004; Zentner, 2005; Liebowitz, 2006) and movies (De Vany \& Walls, 2007; Hennig-Thurau, Henning \& Sattler, 2007; Rob \& Waldfogel, 2007), which typically find evidence of reduced revenues as a result of pirated materials being used as a substitute for paid legal consumption. A caveat to this broad conclusion would be that individuals downloading larger volumes of material are found to express a higher willingness to pay on average for legal alternatives, such as services that allow unlimited legal downloads for a fixed monthly fee. While this finding may be somewhat contrary to expectations, limited supporting evidence has previously been found to support this contention (Pitkar et al., 2008). One possible explanation could be a perceived absence or lack of these services in the marketplace. An alternative interpretation is that 
prolific downloaders simply have higher levels of demand for music and movie content and would therefore naturally be expected to express a larger willingness to pay across all forms of consumption.

The third category relates to the respondent's views on the external effects of internet piracy (P2PBENEFIT, P2PHARM). Our results show a significant increase in the probability of downloading larger quantities of files where consumers express a belief that positive external benefits arise from file sharing (e.g. the practice helps artists to bypass record labels). Conversely, a belief that file sharing imposes external costs (e.g. harms artists and/or producers) associates negatively and significantly with piracy activity. This adds evidence to the debate over hidden benefits to copyright holders resulting from file sharing, where its potential to raise an artist's profile across a wider population is becoming increasingly acknowledged (see Blackburn, 2004; Oberholzer-Gee \& Strumpf, 2007). We find evidence that suggests this effect is stronger among more prolific downloaders.

The fourth broad category of findings relates to an awareness of the law and the effectiveness of legal deterrents (BELEGAL, PROBLOW, PERPPUN, AWAREOTH, EXTPUN, AWAREP2P, AWARESELF). Somewhat surprisingly, our findings show that those who have downloaded larger quantities of material tend to have a greater awareness of the law, being more likely to acknowledge the illegal nature of P2P file sharing sites and the copying of protected content, while also being more aware that they could be punished for their actions by way of imprisonment, fines etc. However, more prolific file sharers are also more likely to hold the belief that the probability of incurring legal sanctions is low. This suggests that even though awareness of illegality is high, the law does not offer an effective constraint on behavior due to the low possibility of apprehension and conviction. This calls into question the effectiveness of high-profile legal action on behalf of record labels and movie studios. Although this finding contradicts evidence from select cross-country analyses 
(Andrés (2006) and Walls (2008)) that identify a significant limiting effect on piracy that stems from the strength of judicial enforcement of intellectual property rights, it is consistent with a growing number of other studies (such as Cohen \& Cornwell, 1989; Fetto, 2000; Hietanen, Huttunen \& Kokkinen, 2008; Lysonski \& Durvasula, 2008; Altschuller \& Benbunan-Fich, 2009) which find consumers to be largely unconcerned by the negative legal consequences of piracy despite an awareness of the illegality of their actions.

The fifth and final broad category of factors relates to external and social influences on behavior (EXTINF, SOCSPHERE). Greater exposure to media campaigns and news related to illegal file sharing is found to negatively associate with levels of piracy, indicating that these measures may serve as an effective constraint on behavior. Knowledge of others who also share files illegally within social or work environments is found to associate positively with piracy, suggesting that the activity represents a social norm for many users, which in turn influences consumption behavior. The finding is also consistent with a number of other studies (such as Givon, Mahajan \& Muller, 1995; Seale, Polakowski \& Schneider, 1998; Gervais, 2003; Lau, 2003; Strahilevitz, 2003; Limayem, Khalifa \& Chin, 2004; Neri, 2005; Morton \& Koufteros, 2008).

\section{Contrasts between music and movie piracy}

The main research question posed by this study relates to the potential for establishing heterogeneous motivations for the illegal sharing of music and movie files. One advantage of the common five-point scale used to measure the numbers of files downloaded is that it allows for a direct and meaningful comparison of the magnitude of the coefficient estimates. While many of the signs and magnitudes are similar across the two model specifications, the regression output does suggest four important distinctions between the two types of behavior. A particular focus has been placed on coefficients that vary in their level of statistical 
significance across the two specifications or where the magnitude of significant coefficients differs by a factor of fifty per cent or more.

The first significant difference relates to socio-demographic factors. Females are found to be significantly less likely to download large quantities of movie files compared to music files. Income follows a similar pattern for both types of piracy, but the positive influence peaks at a higher income for movies than for music. Although the city-dwelling coefficients are found to be significant in both regressions, there is weak evidence to suggest that prolific movie downloaders are more likely to reside in major cities compared to music downloaders. All three findings support the contention that movie downloading is more technologically demanding compared with music, since larger file sizes require faster internet connections, greater digital storage capacities and access to a wider range of devices, codecs etc. required for playback. The practice of movie downloading is found to be (significantly) more likely among richer male city-dwellers; characteristics that have been shown to mirror those of early adopters of new technology and users of the internet in general (Porter \& Donthu, 2006).

The second and perhaps most significant contrast between the two sets of results is that a significantly greater reduction in the level of legal consumption (IMPLEG) is observed in the case of heavy music downloaders compared to movie downloaders, suggesting that pirated music is regarded to be a much better substitute for paid legal consumption than pirated movies. This may also be because some of the means by which movie content is legally consumed (e.g. cinema, Blu-Ray) are less easily substitutable for pirated consumption in the home, since replication of the full experience is less straightforward and more costly. The obvious implication of this finding is that piracy is less likely to lead to the same magnitude of lost revenues for the movie industry compared to the well-publicized reductions already seen within the music industry over the last decade. 
The third major contrast is that a stronger negative association is observed between piracy and a belief that $\mathrm{P} 2 \mathrm{P}$ file sharing causes harm to artists, producers etc. for prolific movie pirates as opposed to music pirates. This is an important finding from a policy perspective, since it indicates that campaigns and other initiatives designed to emphasize the harmful effects of piracy upon the creative industries is likely to be a more effective constraint on illegal movie downloading than music. The findings therefore suggest that public awareness campaigns may prove a more worthwhile investment of time and resources for the movie industry, especially if this creates or plays upon perceptions that pirated movie content is of lower quality than legitimate material.

The fourth and final distinction is that prolific movie pirates are also significantly less likely to hold the belief that punishments affecting the offender's external environment (e.g. being fired from work, evicted from place of residence etc.) can be applied to those found guilty of illegal file sharing, indicating that the threat of these sanctions is less effective in constraining the piracy of movie files than music. This result complements the above by indicating that public awareness campaigns are likely to be less effective if they focus purely on the legal ramifications of movie piracy.

In summary, the findings of this study broadly show the greatest incentives to pirate large quantities of materials to be the possibility of financial savings, as well as the belief that P2P file sharing generates benefits, such as the sampling of new material and allowing artists to bypass movie studios or record companies. The most effective general constraint on behavior is found to be a belief that the content of $\mathrm{P} 2 \mathrm{P}$ file sharing sites is generally of lower quality relative to paid materials. Limited evidence is found to support the view that an awareness of the law or the possibility of harsher punishment offers an effective constraint upon piracy. 
The most significant finding of this paper is that consumers with particularly high levels of demand for illegal movie and music files exhibit significantly different characteristics, attitudes, and behaviors in four key areas. First, prolific movie file sharers are more likely to have a higher monthly income and to be male than prolific music file sharers. Second, consumers that heavily pirate movie files are less likely to reduce their paid consumption as a result of piracy compared with those who download large quantities of music files. Third, our findings show that an awareness of the harm that piracy can cause to the industry (artists, producers etc.) proves to be a more effective constraint on illegal consumption for movie pirates than for music. Finally, prolific movie pirates are found to be significantly less likely to believe that punishments affecting their external environment can be incurred as a result of their actions.

\section{Conclusion}

This study uses Finnish survey evidence to investigate motivations to share copyrighted music and movie files illegally. The greatest incentives for piracy in general are found to be financial and a stronger perception of the benefits associated with file sharing, such as sampling new materials or accessing them ahead of official release. Conversely, the most effective constraint on consumption appears to be a perception that pirated materials are of lower quality than legitimate alternatives. Only limited evidence is found to support the view that an increased awareness of the law or harsher punishments would reduce levels of illegal consumption, at least partly because more prolific pirates are more likely to consider their chances of being caught and punished to be highly remote.

While a comparison between heavier downloaders of illegal music and movie files reveals many common characteristics, demand for different forms of pirated content is not found to be entirely homogenous. Four key factors are found to significantly differ between 
prolific movie and music downloaders, including a lower impact upon paid legal consumption observed for movies compared with music, as well as a greater limiting effect on behavior arising from the belief that piracy harms the relevant industry. Our empirical evidence also suggests that campaigns to raise awareness of the negative consequences of illegal file sharing to the industry are likely to be more effective in constraining movie piracy than for music, especially if they focus on the lower quality of pirated movie files rather than the legal ramifications of $\mathrm{P} 2 \mathrm{P}$ file sharing activity. 


\section{References}

Altschuller, S. \& Benbunan-Fich, R. (2009). Is music downloading the new prohibition? What students reveal through an ethical dilemma. Ethics in Information Technology, $11,49-56$.

Andrés, A.R. (2006). Software piracy and income inequality. Applied Economics Letters, 13(2), 101-105.

Blackburn, D. (2004). Online piracy and recorded music sales. Harvard University Department of Economics Working Paper.

Christin, N., Weigend, A.S. \& Chuang, J. (2005). Content availability, pollution and poisoning in file sharing peer-to-peer networks. EC '05: Proceedings of the 6th ACM conference on Electronic Commerce, 68-77, New York, ACM Press.

Cohen, E., \& Cornwell, L. (1989). College students believe piracy is acceptable. Journal of Information Systems Education, 1(3), 2-5.

De Vany, A.S., \& Walls, W.D. (2007). Estimating the effects of movie piracy on box office revenue. Review of Industrial Organization, 30, 291-301.

Fetto, J. (2000). Penny for your thoughts. American Demographics, 22(9), 8-9.

Freestone, O., \& Mitchell, V. (2004). Generation Y attitudes towards e-ethics and internet related misbehaviors. Journal of Business Ethics, 54(2), 121-128.

Gervais, D.J. (2003). The price of social norms: towards a liability regime for file sharing. Journal of Intellectual Property Law, 12(1), 39-74. 
Givon, M., Mahajan, V., \& Muller, E. (1995). Software piracy: estimation of lost sales and the impact on software diffusion. Journal of Marketing, 59, 29-37.

Hennig-Thurau, T., Henning, V., \& Sattler, H. (2007). Consumer file sharing of motion pictures. Journal of Marketing, 71, 1-18.

Hietanen, H., Huttunen, A., \& Kokkinen, H. (2008). Criminal friends of entertainment: analyzing results from recent peer-to-peer surveys. SCRIPT-ed, 5(1), 31-49.

Hirshleifer, J. \& Riley, J.G. (1992). The analytics of uncertainty and information. Cambridge University Press, Cambridge, UK.

Hong, S.H. (2004). The effect of Napster on recorded music sales: evidence from the Consumer Expenditure Survey. Stanford University SIEPR Discussion Paper, No. 03018.

Huang, C.Y. (2005). File sharing as a form of music consumption. International Journal of Electronic Commerce, 9(4), 37-55.

Hui, K., \& Png, I. (2003). Piracy and the legitimate demand for recorded music. Contributions to Economic Analysis and Policy, 2(1), 1-22.

Human Capital (2009). Youth and music survey. Marrakesh Records Report, February 2009.

LaRose, R., Lai, Y., Lange, R., Love, B., \& Wu, Y. (2005). Sharing or piracy? An exploration of downloading behavior. Journal of Computer Mediated Communication, 11(1): Article 1. (Retrieved 5 October 2011, http://jcmc.indiana.edu/vol11/issuel/larose.html). 
Lau, E.K.W. (2003). An empirical study of software piracy. Business Ethics: a European Review, 12(3), 233-245.

Liebowitz, S.J. (2006). Testing file sharing's impact by investigating record sales in cities. University of Texas at Dallas Center for the Analysis of Property Rights and Innovation Publication, 05-02.

Limayem, M., Khalifa, M., \& Chin, W.W. (2004). Factors motivating software piracy: a longitudinal study. Engineering Management, IEEE Transactions on, 51(4), 414-425.

Lysonski, S., \& Durvasula, S. (2008). Digital piracy of MP3s: consumer and ethical predispositions. Journal of Consumer Marketing, 25(3), 167-178.

Morton, N.A., \& Koufteros, X. (2008). Intention to commit online music piracy and its antecedents: an empirical investigation. Structural Equation Modeling, 15(3), 491512.

Neri, G. (2005). Sticky fingers or sticky norms? Unauthorized music downloads and unsettled social norms. Georgetown Law Journal, 93, 733-758.

Oberholzer-Gee, F., \& Strumpf, K. (2007). The effect of file sharing on record sales: an empirical analysis. Journal of Political Economy, 115, 1-42.

Parameswaran, M., Susarla, A., \& Whinston, A.B. (2001). P2P networking: an informationsharing alternative. IEEE Computer, 34(7), 31-38.

Pew Internet and American Life Project (2003). Pew Internet Project Data Memo, July 2003. 
Pitkar, K., Rajpathak, S., Motwani, T., \& Mahendiran, A. (2008). Minimizing revenue loss due to piracy: an early internet release of motion picture. ITP Interdisciplinary Telecommunications Program, Capstone Papers, May 2008.

Porter, C.E., \& Donthu, N. (2006). Using the technology acceptance model to explain how attitudes determine internet usage: the role of perceived access barriers and demographics. Journal of Business Research, 59, 999-1007.

Rob, R., \& Waldfogel, J. (2007). Piracy on the silver screen. Journal of Industrial Economics, 55(3), 379-395.

Schuloze, H. \& Mochalski, K. (2007). Internet Study 2007, Technical Report, ipoque, GmbH.

Seale, D.A., Polakowski, M., \& Schneider, S. (1998). It's not really theft! Personal and workplace ethics that enable software piracy. Behavior and Information Technology, $17(1), 27-40$.

Shanahan, K.J., \& Hyman, M.R. (2010). Motivators and enablers of SCOURing: a study of online piracy in the US and UK. Journal of Business Research, 63, 1095-1102.

Sims, R.R., Cheng, H.K., \& Teegan, H. (1996). Toward a profile of student software piraters. Journal of Business Ethics, 15, 839-849.

Sinha, R.K., \& Mandel, N. (2008). Preventing digital music piracy: the carrot or the stick? Journal of Marketing, 72, 1-15.

Strahilevitz, L.J. (2003). Charismatic code, social norms and the emergence of cooperation on the file sharing networks. Virginia Law Review, 89(3), 505-595. 
Walls, W.D. (2008). Cross-country analysis of movie piracy. Applied Economics, 40(5), 625632.

Zentner, A. (2005). File sharing and international sales of copyrighted music: an empirical analysis with a panel of countries. Topics in Economic Analysis and Policy, 5(21), 115. 
Table 1: Construction of Dependent Variables

\begin{tabular}{|c|c|c|c|c|c|}
\hline \multicolumn{3}{|l|}{ Music } & \multicolumn{3}{|l|}{ Movies } \\
\hline $\begin{array}{l}\text { Respondent admits to } \\
\text { having illegally } \\
\text { downloaded }(x) \\
\text { quantity of music } \\
\text { albums }\end{array}$ & $\begin{array}{l}\text { Value in } \\
\text { construction of } \\
\text { ordered } \\
\text { variable }\end{array}$ & $\begin{array}{l}\text { Percentage of } \\
\text { sample }(\mathrm{N}=6103)\end{array}$ & $\begin{array}{l}\text { Respondent admits } \\
\text { to having illegally } \\
\text { downloaded (y) } \\
\text { quantity of movies }\end{array}$ & $\begin{array}{l}\text { Value in } \\
\text { construction of } \\
\text { ordered variable }\end{array}$ & $\begin{array}{l}\text { Percentage of } \\
\text { sample }(N=6103)\end{array}$ \\
\hline 0 & 0 & $18.3 \%$ & 0 & 0 & $22.3 \%$ \\
\hline $1-100$ & 1 & $19.9 \%$ & $1-10$ & 1 & $14.5 \%$ \\
\hline $101-1,000$ & 2 & $18.8 \%$ & $11-100$ & 2 & $20.0 \%$ \\
\hline $1,001-10,000$ & 3 & $30.2 \%$ & $101-200$ & 3 & $15.2 \%$ \\
\hline $10,001+$ & 4 & $12.8 \%$ & $201+$ & 4 & $28.0 \%$ \\
\hline
\end{tabular}




\begin{tabular}{|c|c|c|c|c|c|}
\hline \multirow[t]{10}{*}{ SOCDEM } & Socio-demographic control variables & Loadings & Range & Mean & Std Dev \\
\hline & Age & - & $7-84$ & 27.8 & 9.6 \\
\hline & Gender (Female) & - & $0-1$ & 0.06 & - \\
\hline & Area of residency (City) & - & $0-1$ & 0.66 & - \\
\hline & Monthly personal income (Less than $€ 500$ ) - BASE & - & $0-1$ & 0.33 & - \\
\hline & Monthly personal income (€500-€1500) & - & $0-1$ & 0.19 & - \\
\hline & Monthly personal income $(€ 1501-€ 2500)$ & - & $0-1$ & 0.22 & - \\
\hline & Monthly personal income (€2501-€3500) & - & $0-1$ & 0.15 & - \\
\hline & Monthly personal income (€3501-€5000) & - & $0-1$ & 0.07 & - \\
\hline & Monthly personal income (More than $€ 5000$ ) & - & $0-1$ & 0.03 & - \\
\hline BELEGAL & Believes content to be legal or mostly legal & Loadings & Range & Mean & Std Dev \\
\hline Cronbach's & Direct Connect & 0.85 & $1-5$ & 2.80 & 0.97 \\
\hline \multirow[t]{5}{*}{ Alpha $=0.90$} & BitTorrent & 0.72 & $1-5$ & 3.14 & 1.01 \\
\hline & Kazaa & 0.82 & $1-5$ & 2.68 & 1.00 \\
\hline & PirateBay & 0.79 & $1-5$ & 2.74 & 1.05 \\
\hline & eDonkey & 0.86 & $1-5$ & 2.80 & 0.95 \\
\hline & Symtorrent & 0.78 & $1-5$ & 2.99 & 0.72 \\
\hline NEGP2P & Negative perceptions of $P 2 P$ content & Loadings & Range & Mean & Std Dev \\
\hline Cronbach's & P2P content often contains viruses & 0.84 & $1-5$ & 2.03 & 1.24 \\
\hline \multirow[t]{4}{*}{ Alpha $=0.85$} & P2P content does not match description & 0.82 & $1-5$ & 2.36 & 1.28 \\
\hline & $\mathrm{P} 2 \mathrm{P}$ content is difficult to find & 0.57 & $1-5$ & 1.89 & 1.25 \\
\hline & $\mathrm{P} 2 \mathrm{P}$ content is often of poor quality & 0.68 & $1-5$ & 2.19 & 1.28 \\
\hline & $\mathrm{P} 2 \mathrm{P}$ content often contains malware & 0.86 & $1-5$ & 2.03 & 1.20 \\
\hline EXTINF & Influenced by external sources & Loadings & Range & Mean & Std Dev \\
\hline Cronbach's & Finreactor trial & 0.63 & $1-5$ & 3.10 & 0.56 \\
\hline \multirow[t]{7}{*}{ Alpha $=0.80$} & Ban on importing unauthorized CDs and DVDs & 0.64 & $1-5$ & 2.94 & 0.41 \\
\hline & New copyright law & 0.63 & $1-5$ & 2.93 & 0.68 \\
\hline & Campaigning for awareness of copyright law & 0.69 & $1-5$ & 2.91 & 0.56 \\
\hline & Information obtained from school & 0.57 & $1-5$ & 2.94 & 0.36 \\
\hline & Admonition of parents or friends & 0.68 & $1-5$ & 2.98 & 0.28 \\
\hline & News of online piracy & 0.73 & $1-5$ & 2.98 & 0.54 \\
\hline & P2P related attitudes of my partner or user of the same computer & 0.60 & $1-5$ & 2.89 & 0.48 \\
\hline PROBLOW & Probability of incurring punishment is low & Loadings & Range & Mean & Std Dev \\
\hline Cronbach's & Smaller than shoplifting & 0.84 & $1-5$ & 0.90 & - \\
\hline \multirow[t]{4}{*}{ Alpha $=0.86$} & Smaller than free-riding on public transport & 0.84 & $1-5$ & 0.89 & - \\
\hline & Smaller than getting a parking ticket & 0.84 & $1-5$ & 0.88 & - \\
\hline & Smaller than being caught speeding & 0.80 & $1-5$ & 0.85 & - \\
\hline & Smaller than not paying TV license fee & 0.66 & $1-5$ & 0.80 & - \\
\hline P2PBENEFIT & Believes file sharing generates external benefits & Loadings & Range & Mean & Std Dev \\
\hline Cronbach’s & P2P file sharing can be used to sample new material & 0.61 & $1-5$ & 4.32 & 1.12 \\
\hline \multirow[t]{4}{*}{ Alpha $=0.77$} & P2P file sharing increases sales via legal channels & 0.66 & $1-5$ & 3.25 & 1.33 \\
\hline & P2P file sharing allows access to material not available via legal channels & 0.61 & $1-5$ & 4.41 & 0.99 \\
\hline & Using P2P supports technical development & 0.67 & $1-5$ & 3.67 & 1.29 \\
\hline & Using P2P helps artists to bypass record companies & 0.66 & $1-5$ & 3.26 & 1.36 \\
\hline
\end{tabular}




\begin{tabular}{|c|c|c|c|c|c|}
\hline POSLEGAL & Positive opinion of legal download sites & Loadings & Range & Mean & Std Dev \\
\hline Cronbach's & Immediate access to material & 0.75 & $1-5$ & 3.26 & 0.80 \\
\hline \multirow[t]{4}{*}{ Alpha $=0.849$} & Easy to make purchases & 0.79 & $1-5$ & 3.22 & 0.80 \\
\hline & Can purchase individual tracks & 0.67 & $1-5$ & 3.30 & 0.82 \\
\hline & Easy to find what you want & 0.75 & $1-5$ & 3.12 & 0.76 \\
\hline & Safe to use & 0.71 & $1-5$ & 3.20 & 0.72 \\
\hline PERPUN & Perceived applicable (personal) punishments & Loadings & Range & Mean & Std Dev \\
\hline Cronbach's & Computer can be confiscated & 0.82 & $0-1$ & 0.90 & - \\
\hline \multirow[t]{3}{*}{ Alpha $=0.71$} & File sharer can be incarcerated & 0.46 & $0-1$ & 0.55 & - \\
\hline & File sharer can be fined & 0.84 & $0-1$ & 0.93 & - \\
\hline & File sharer can be made to pay damages to rights owners & 0.84 & $0-1$ & 0.92 & - \\
\hline IMPLEG & Impact on (reduced) consumption of legal media & Loadings & Range & Mean & StdDev \\
\hline Cronbach's & Reduced consumption of TV programs & 0.43 & $1-5$ & 2.91 & 1.00 \\
\hline \multirow[t]{4}{*}{ Alpha $=0.73$} & Reduced consumption of digital download store movies & 0.79 & $1-5$ & 3.02 & 0.53 \\
\hline & Reduced consumption of digital download store music files & 0.76 & $1-5$ & 3.00 & 0.63 \\
\hline & Reduced consumption of DVDs purchased over the Internet & 0.80 & $1-5$ & 2.85 & 0.75 \\
\hline & Reduced consumption of CDs purchased over the Internet & 0.74 & $1-5$ & 2.85 & 0.81 \\
\hline AWAREOTH & Awareness of copyright law - material purchased by others & Loadings & Range & Mean & Std Dev \\
\hline Cronbach's & As far as I am aware, it is legal to copy materials purchased by a friend & 0.80 & $0-1$ & 0.41 & - \\
\hline \multirow[t]{3}{*}{ Alpha $=0.78$} & As far as I am aware, it is legal to copy materials copied by a friend & 0.70 & $0-1$ & 0.21 & - \\
\hline & As far as I am aware, it is legal to copy materials borrowed from a library & 0.78 & $0-1$ & 0.39 & - \\
\hline & As far as I am aware, it is legal to copy materials rented from a store & 0.67 & $0-1$ & 0.16 & - \\
\hline EXTPUN & Perceived applicable (external) punishments & Loadings & Range & Mean & Std Dev \\
\hline Cronbach's & File sharers office can be closed if files are shared at work & 0.74 & $0-1$ & 0.18 & - \\
\hline \multirow[t]{4}{*}{ Alpha $=0.66$} & File sharer can be fired from school or job & 0.42 & $0-1$ & 0.49 & - \\
\hline & File sharer's employer may be subject to business restrictions & 0.75 & $0-1$ & 0.17 & - \\
\hline & File sharer can be evicted & 0.55 & $0-1$ & 0.08 & - \\
\hline & File sharer's or parent's place of work can be put under surveillance & 0.65 & $0-1$ & 0.24 & - \\
\hline SAVINGS & File sharing allows for (financial/time) savings & Loadings & Range & Mean & Std Dev \\
\hline Cronbach's & Can access files for lower cost & 0.77 & $1-5$ & 4.26 & 1.06 \\
\hline \multirow[t]{2}{*}{ Alpha $=0.70$} & Can avoid credit card payments & 0.80 & $1-5$ & 4.01 & 1.25 \\
\hline & Can access material before it is available in Finland & 0.50 & $1-5$ & 4.38 & 1.04 \\
\hline P2PHARM & P2P file sharing causes harm & Loadings & Range & Mean & Std Dev \\
\hline Cronbach's & By using P2P file-sharing sites I may cause damage to the artists & 0.65 & $1-5$ & 2.46 & 1.38 \\
\hline \multirow[t]{2}{*}{ Alpha $=0.67$} & By using P2P file-sharing sites I may cause damage to the producers & 0.68 & $1-5$ & 2.66 & 1.49 \\
\hline & I can get caught and punished for using P2P file sharing sites & 0.55 & $1-5$ & 3.05 & 1.4 \\
\hline SOCSPHERE & Influence from social sphere & Loadings & Range & Mean & Std Dev \\
\hline Cronbach's & Knows friends that download material illegally & 0.42 & $0-1$ & 0.84 & - \\
\hline \multirow[t]{3}{*}{ Alpha $=0.61$} & Knows persons in the family group that download material illegally & 0.67 & $0-1$ & 0.39 & - \\
\hline & Knows other relatives that download material illegally & 0.72 & $0-1$ & 0.36 & - \\
\hline & Knows work colleagues that download material illegally & 0.67 & $0-1$ & 0.46 & - \\
\hline AWAREP2P & Awareness of copyright law - file sharing & Loadings & Range & Mean & Std Dev \\
\hline Cronbach's & I understand that it is legal to download unauthorized music from P2P sites & 0.69 & $0-1$ & 0.10 & - \\
\hline \multirow[t]{2}{*}{ Alpha $=0.63$} & I understand that it is legal to make a copy of a TV program from P2P sites & 0.73 & $0-1$ & 0.24 & - \\
\hline & I understand that it is legal to upload a TV program I have recorded to YouTube & 0.63 & $0-1$ & 0.12 & - \\
\hline
\end{tabular}




\begin{tabular}{|c|c|c|c|c|c|}
\hline AWARESELF & Awareness of copyright law - material purchased by self & Loadings & Range & Mean & Std Dev \\
\hline Cronbach's & I understand that it is legal to make a copy of a CD that I have purchased for my own use & 0.58 & $0-1$ & 0.90 & - \\
\hline \multirow[t]{4}{*}{ Alpha $=0.54$} & I understand that it is legal to download music from websites & 0.44 & $0-1$ & 0.65 & - \\
\hline & I understand that it is legal to record a TV program & 0.69 & $0-1$ & 0.93 & - \\
\hline & I understand that it is legal to copy a TV program recorded by a friend & 0.45 & $0-1$ & 0.54 & - \\
\hline & I understand that it is legal to watch a TV program in YouTube & 0.64 & $0-1$ & 0.83 & - \\
\hline WTPALT & Willingness to pay for alternatives & Loadings & Range & Mean & Std Dev \\
\hline Cronbach's & Conversion of illegal to legal files & 0.64 & $1-5$ & 2.53 & 1.50 \\
\hline \multirow[t]{2}{*}{ Alpha $=0.54$} & Unlimited download service of movies and music & 0.68 & $1-5$ & 3.54 & 1.61 \\
\hline & Unlimited download service of music & 0.63 & $1-5$ & 2.00 & 1.54 \\
\hline
\end{tabular}




\begin{tabular}{|c|c|c|c|c|}
\hline \multirow{2}{*}{$\begin{array}{l}\text { VARIABLE } \\
\text { FEMALE }\end{array}$} & \multicolumn{2}{|c|}{ VOL MUS } & \multicolumn{2}{|c|}{ VOL MOV } \\
\hline & -0.295 & $* * *$ & -0.569 & $* * *$ \\
\hline AGE & -0.021 & $* * *$ & -0.024 & *** \\
\hline CITY & -0.057 & & 0.044 & \\
\hline Y1500 & 0.155 & * & 0.282 & $* * *$ \\
\hline Y2500 & 0.008 & & 0.124 & \\
\hline Y3500 & -0.197 & * & -0.059 & \\
\hline Y5000 & -0.346 & $* * *$ & -0.247 & $*$ \\
\hline Y5000P & -0.245 & & -0.078 & \\
\hline BELEGAL & -0.277 & $* * *$ & -0.237 & ${ }^{* * *}$ \\
\hline NEGP2P & -0.854 & $* * *$ & -0.954 & *** \\
\hline EXTINF & -0.254 & $* * *$ & -0.264 & *** \\
\hline PROBLOW & 0.351 & $* * *$ & 0.362 & $* * *$ \\
\hline P2PBENEFIT & 0.702 & $* * *$ & 0.728 & ${ }^{* * *}$ \\
\hline POSLEGAL & -0.227 & $* * *$ & -0.223 & ${ }^{* * *}$ \\
\hline PERPUN & 0.180 & $* * *$ & 0.245 & $* * *$ \\
\hline IMPLEG & 0.099 & $* * *$ & -0.021 & \\
\hline AWAREOTH & 0.105 & $* * *$ & 0.091 & $* * *$ \\
\hline EXTPUN & 0.080 & $* * *$ & 0.011 & \\
\hline SAVINGS & 0.660 & $* * *$ & 0.623 & $* * *$ \\
\hline P2PHARM & -0.160 & $* * * *$ & -0.279 & $* * *$ \\
\hline SOCSPHERE & 0.757 & $* * *$ & 0.723 & *** \\
\hline AWAREP2P & 0.057 & $*$ & 0.074 & $* * *$ \\
\hline AWARESELF & -0.020 & & -0.028 & \\
\hline WTPALT & 0.186 & $* * *$ & 0.248 & *** \\
\hline LR Statistic & 3820 & $* * *$ & 3922 & $* * *$ \\
\hline Log Likelihood & -7676 & & -7673 & \\
\hline
\end{tabular}

